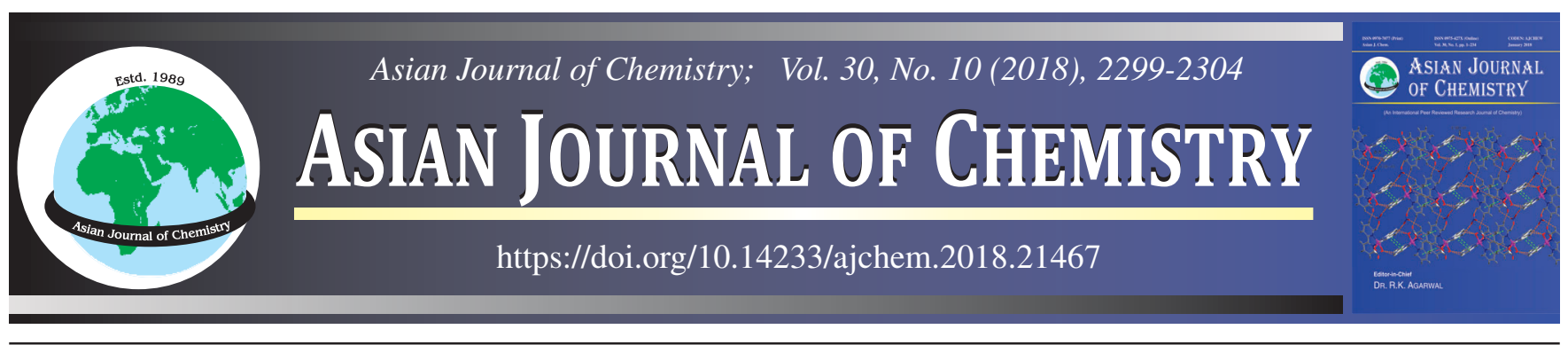

\title{
Emulsion Polymerization of Poly(Methacrylic Acid) Nanoparticles: Effects of Different Cationic Surfactants
}

Noor Aniza Harun*, Nur Shahiera Md Tahier, Nur Nasyita Kamaruddin, Mazidah Mamat and Syara Kassim

Advance Nano Materials Research Group, School of Fundamental Science, Universiti Malaysia Terengganu, 21030, Kuala Nerus, Terengganu, Malaysia

*Corresponding author: Fax: +60 9 6683608; Tel: +60 9 6683317; E-mail: nooraniza@umt.edu.my

Received: 22 May 2018;

Accepted: 16 July 2018;

Published online: 31 August 2018;

AJC-19062

The synthesis of poly(methacrylic acid) (PMAA) nanoparticles were prepared via emulsion polymerization technique by using different types of cationic surfactants and potassium persulfate as water soluble initiator. The different ranges of cationic surfactants, namely, cetyltrimethylammonium bromide (CTAB), tetradecyl trimethylammonium bromide (TTAB) and cetylpyridinium chloride (CPC) were used at different concentration (below, equivalent and above CMC). FTIR was conducted to observe the absorption peaks at $1600-1500$ | $\mathrm{cm}^{-1}, 1800-1700 \mathrm{~cm}^{-1}, 2700-2500 \mathrm{~cm}^{-1}$ and 3300-3000 $\mathrm{cm}^{-1}$, represents $\mathrm{C}=\mathrm{O}$ stretching, C-O-C vibration, $\mathrm{CH}_{3}$ and $\mathrm{O}-\mathrm{H}$ stretching, respectively. SEM was performed to determine the particle size and morphology of PMAA nanoparticles where it showed that the particle size of PMAA nanoparticles between $400-600 \mathrm{~nm}$. The weight decomposition data was obtained from TGA where it showed that the PMAA nanoparticles synthesized using TTAB as cationic surfactant prepared at equivalent CMC is the most stable PMAA nanoparticles.

1

Keywords: Hydrophilic polymer nanoparticles, Emulsion polymerization, Methacrylic acid, Biodegradable.

\section{INTRODUCTION}

Nanoparticles are defined as submicron-size solid between 100 to $500 \mathrm{~nm}$ that can be either biodegradable or non-biodegradable [1]. Nanoparticles can be constructed from various materials (e.g. polymers, lipids, metals, magnetic) and widely utilized in various industrial application like optical [2], catalyst [3], thermal [4], electrical [5], mechanical [6] and magnetic function [7]. In particular, polymeric nanoparticles have received great attention on account of their versatility in which they can host a wide range of active components including chemotherapeutics, contrast agents, proteins and nucleic acids, for various bio-medical applications [8].

The criteria for the ideal polymeric nanoparticles especially in the development of biomedical fields should be easy to synthesize, inexpensive, biocompatible and biodegradable, non-toxic and water soluble [9]. Hydrophilic polymer nanoparticles are the type of polymer chain that contains substitution of hydrophilic groups at the backbone either from anionic, cationic or amphoteric. This type of polymer can be divided into two main types, synthetic and natural. Nowadays, synthetic hydrophilic polymer nanoparticles become attractive alternatives for biomedical applications especially in the novel drug delivery system because of their solubility in water and low intrinsic toxicity of polymer nanoparticles. Moreover, it can also enhance the physical and chemical stability of drugs and can prevent the aggregation of the drugs [10]. Amongst numerous types of synthetic hydrophilic polymer nanoparticles, poly(methacrylic acid) (PMAA) is attracted high interest in biomedical applications due to its biodegradability and biocompatibility. The carboxyl groups in PMAA provide binding sites for cationic anticancer drugs such as doxorubicin [11]. In the previous study, we have successfully synthesized PMAA nanoparticles via emulsion polymerization technique utilizing anionic type of surfactant at different concentrations [12].

Emulsion polymerization is one of the various polymerization methods that can be employed to produce high molecular weight synthetic polymer nanoparticles with no or negligible volatile organic compounds. The main components involved in emulsion polymerization are monomer, surfactant and initiator which composed in aqueous medium in the presence of heat, pressure or catalysis that can change the chemical

This is an open access journal, and articles are distributed under the terms of the Creative Commons Attribution-NonCommercial 4.0 International (CC BY-NC 4.0) License, which allows others to copy and redistribute the material in any medium or format, remix, transform, and build upon the material, as long as appropriate credit is given and the new creations are licensed under the identical terms. 
bonds and resulting them to crosslink with one another [13]. The polymerization is performed in the inner site of micelle and the final products of emulsion polymerization are colloidally and thermodynamically stable polymer latexes.

Surfactant or surface active agent is vital component in emulsion polymerization. Selection of correct surfactant is important in the development emulsion polymerization process. Surfactant can lead a fast rate polymerization, minimize coagulum or fouling in the reactor, prevent an unacceptably high viscosity during polymerization that can cause poor heat transfer and can also maintain or improve properties of final product [13]. The nature and amount of the surfactant used in the formulation completely can affect the size distribution, structure and stability of resulting emulsions and nanoparticles [14]. There are several types of surfactant such as anionic, cationic, non-ionic, gemini and zwitterionic surfactant [15]. Cationic surfactant is a type of surfactant with positive charge and, generally it is not really favouable due to high cost in comparison to anionic surfactant. Even though, cationic surfactant is not excellent foaming agent like anionic surfactant but they can exhibit positive charge that allow them to absorb negatively charged particles. Sarac et al. [16] have developed emulsion polymerization of vinyl acetate in the presence of a new cationic polymer surfactant. The effect of new cationic polymeric surfactant and two thermal initiators on the physiochemical properties of a semi-continuous cationic emulsion polymerization of vinyl acetate have been studied.

In previous work, we have successfully investigated the effects of different types of non-ionic surfactants towards the formation PMAA nanoparticles prepared via emulsion polymerization technique [17]. In this work we describe a synthetic route to prepare PMAA nanoparticles by using different types of cationic surfactants, namely, cetyltrimethylammonium bromide (CTAB), tetradecyl trimethylammonium bromide (TTAB) and cetylpyridinium chloride (CPC). It is worth to be noted that, the main difference between $\mathrm{CTAB}$ and TTAB is their hydrocarbon chain length where CTAB has longer chain length (16 carbon chains) in comparison to TTAB that only have 14 carbons chains. Meanwhile, CPC has 16 carbon chains and classified as cationic quaternary ammonium.

\section{EXPERIMENTAL}

Methacrylic acid (MMA) monomer, cationic surfactants of cetyltrimethylammonium bromide (CTAB), tetradecyl trimethylammonium bromide (TTAB) and cetylpyridinium chloride (CPC) and water soluble initiator, potassium persulfate (KPS) were purchased from Sigma Aldrich and used as received without further purification. Distilled water was used throughout the experiment.

General procedure of emulsion polymerization of PMAA nanoparticles: The emulsion polymerization of PMAA nanoparticles was performed in $250 \mathrm{~mL}$ two neck-round bottom flask equipped with a reflux condenser, magnetic stirrer and thermometer. MMA monomer $(5 \mathrm{~mL})$, distilled water $(90 \mathrm{~mL})$ and different concentration of cationic surfactants (below, equivalent and above CMC) (Table-1) were added into the round bottom flask.

Polymerization was carried out using three different types of surfactants, TTAB, CTAB and CPC. The reaction mixture was purged with nitrogen for 10-15 min to remove any dissolve oxygen [18]. The emulsion mixture was heated to $70{ }^{\circ} \mathrm{C}$ and aqueous solution of potassium persulfate was added to initiate polymerization and the reaction was continued to complete for $3 \mathrm{~h}$. The resulting emulsion was cooled down at room temperature and the remaining solvent was removed by rotary evaporator.

Fourier transform infrared spectroscopy (FTIR): FTIR spectroscopy was determined using Perkin Elmer Spectrum 100 with sampling range of $4000-800 \mathrm{~cm}^{-1}$ and 16 times of scan number. The polymer samples were prepared using KBR disk ( $3 \%$ of KBR) and FTIR spectra were measured on a Nicolet 520 FTIR Spectrophotometer.

Scanning electron microscopy (SEM): The polymer nanoparticles samples were mounted on SEM holder and coated with gold by Auto Fine Coater (JEOL) to prevent accumulation of electrostatic charge on the surface of the samples. The morphology of polymer nanoparticles was observed by SEM (JEOL, JSM6360LA) at $10-15 \mathrm{kV}$ accelerating voltage.

Thermogravimetry analyzer (TGA): The dynamic weight loss tests were conducted on a TA Instruments 2050 thermogravimetric analyzer. All tests were conducted in an $\mathrm{N}_{2}$ purged ( $25 \mathrm{~mL} / \mathrm{min}$ ) using sample weights of 5-10 mg over a temperature range $20-600{ }^{\circ} \mathrm{C}$ with scan rate of $10^{\circ} \mathrm{C} / \mathrm{min}$.

Dynamic light scattering (DLS): Dynamic light scattering (DLS) technique was used to determine the particles size of PMAA nanoparticles. The characterization was performed by DLS measurement using a Malvern Zetasizer instrument at $25 \pm 0.1^{\circ} \mathrm{C}$ and a scattering angle of $173^{\circ}$ (backscatter detection). Polymer nanoparticles sample (5 $\mathrm{mg}$ ) was dissolved in

\begin{tabular}{|c|c|c|c|c|c|}
\hline \multirow[b]{3}{*}{ Polymer samples } & \multicolumn{5}{|c|}{$\begin{array}{l}\text { TABLE-1 } \\
\text { EMULSION POLYMERIZATION OF PMAA NANOPARTICLES USING } \\
\text { CATIONIC SURFACTANTS PREPARED AT VARIOUS CONCENTRATIONS }\end{array}$} \\
\hline & \multicolumn{5}{|c|}{ Composition } \\
\hline & MAA monomer $(\mathrm{mL})$ & Cationic surfactants & $\begin{array}{l}\text { Surfactants concentration } \\
\text { (M) }\left[10^{-3}(\mathrm{~mol} / \mathrm{L})\right]\end{array}$ & Distilled water $(\mathrm{mL})$ & $\begin{array}{c}\text { Potassium } \\
\text { persulfate }(\mathrm{g})\end{array}$ \\
\hline $\begin{array}{l}\text { PMAА }_{\mathrm{CTAB} \_1} 1 \\
\text { PMAA }_{\mathrm{CTAB} \_} 2 \\
\text { PMAA }_{\mathrm{CTAB} \_} 3\end{array}$ & 5.00 & CTAB & $\begin{array}{l}0.70 \text { (below CMC) } \\
0.95 \text { (at CMC) } \\
1.5 \text { (above CMC) }\end{array}$ & 90 & 0.12 \\
\hline $\begin{array}{l}\text { PMAA }_{\text {TTAB_1 }} 1 \\
\text { PMAA }_{\text {TTAB_2 }} \\
\text { PMAA }_{\text {TTAB_ } 3} \\
\end{array}$ & 5.00 & TTAB & $\begin{array}{l}2.50 \text { (below CMC) } \\
3.50 \text { (at CMC) } \\
4.50 \text { (above } \mathrm{CMC}) \\
\end{array}$ & 90 & 0.12 \\
\hline $\begin{array}{l}\text { PMAA }_{\text {CPC } \_1} 1 \\
\text { PMAA }_{\text {CPC } \_2} \\
\text { PMAA }_{\text {CPC } \_3}\end{array}$ & 5.00 & CPC & $\begin{array}{l}0.70 \text { (below CMC) } \\
0.90(\text { at } \mathrm{CMC}) \\
1.10 \text { (above } \mathrm{CMC})\end{array}$ & 90 & 0.12 \\
\hline
\end{tabular}


$10 \mathrm{~mL}$ distilled water. Then, the sample solution was placed in glass cuvette and measurements were performed 5 times.

\section{RESULTS AND DISCUSSION}

Synthesis of PMAA nanoparticles via emulsion polymerizations: PMAA nanoparticles were successfully obtained via emulsion polymerization technique utilizing different types of cationic surfactants; CTA, TTAB and CPC at different concentrations of below, equivalent and above critical micelles concentration (CMC). The polymerization was initiated by aqueous KPS solution and water was used as dispersion medium. Emulsion polymerization of MMA monomer in the presence of cationic surfactants shows that the emulsion dispersion obtained as translucent clear solution and not in a milky conventional emulsion dispersion. This observation is different from the emulsion polymerization of PMAA nanoparticles prepared using anionic and non-ionic types surfactants $[12,17]$.

Physical appearances of PMAA nanoparticles: According to the physical appearances of PMAA nanoparticles obtained from emulsion polymerization of MAA monomers comprising various types of cationic surfactants (CTAB, TTAB and CPC) at different concentrations (below, equivalent and above $\mathrm{CMC}$ ), it was observed that all PMAA nanoparticles samples were produced in the form of hydrogel (Fig. 1). Ahmed [19] has reported in the previous study that hydrogels are normally obtained from polar monomer like MAA monomers prepared via emulsion polymerization method.
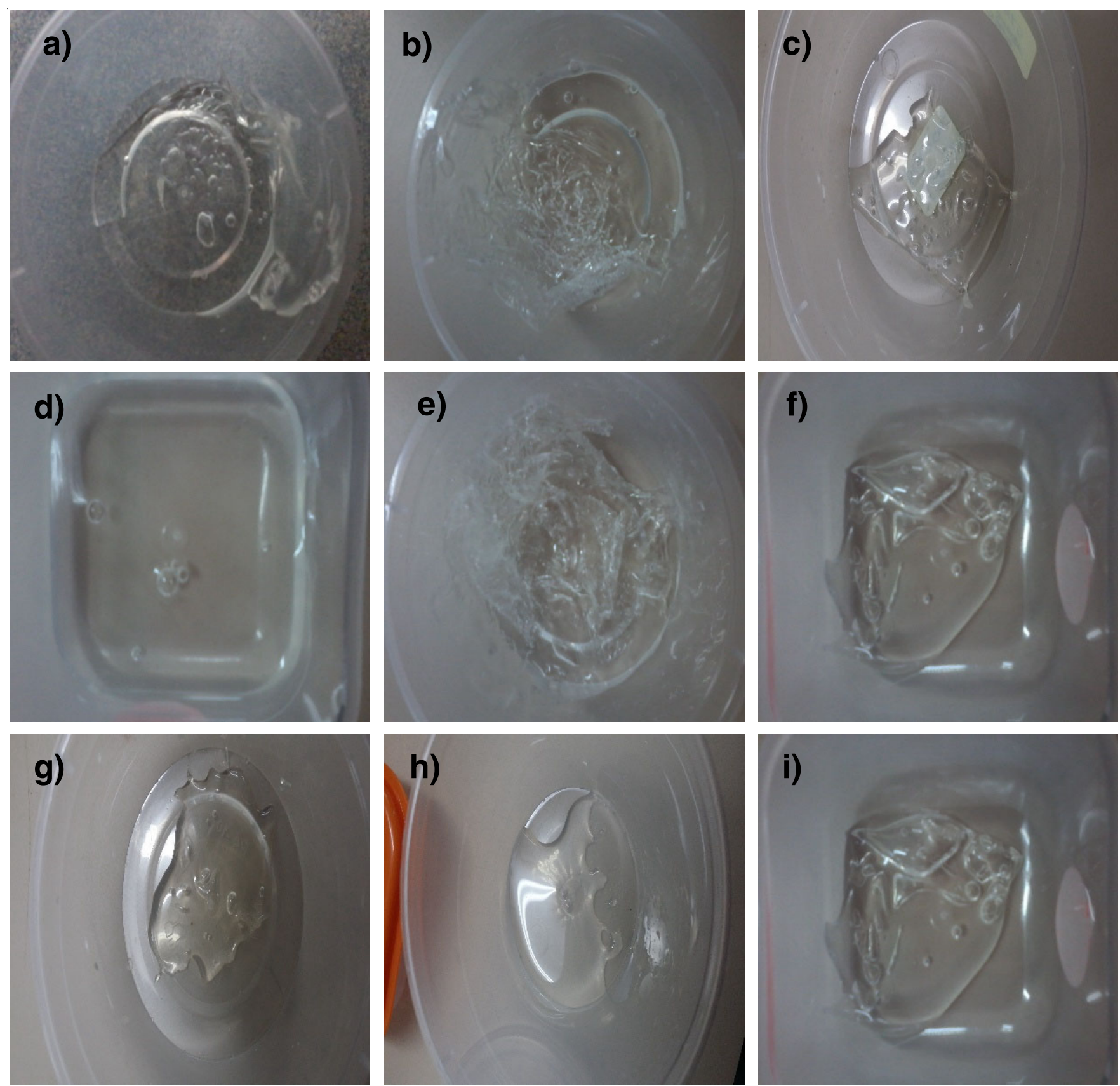

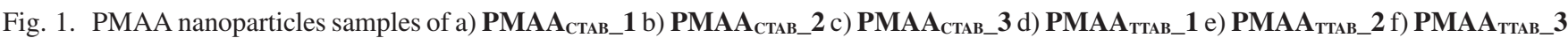

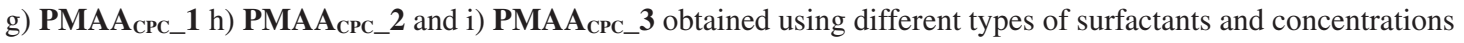


Fourier transform infrared spectroscopy (FTIR): Fig. 2 represents the IR spectra of PMAA nanoparticles obtained by using different types of cationic surfactant at different concentration (below, equivalent and above $\mathrm{CMC}$ ). The broad peak (Fig. 2) in the range of $3400-3200 \mathrm{~cm}^{-1}$ is due to the existence of hydroxyl group $(\mathrm{O}-\mathrm{H})$ in PMAA nanoparticles. The IR bands in region of $3000-2800 \mathrm{~cm}^{-1}$ is belong to the characteristic of $\mathrm{C}-\mathrm{H}$ stretching. The strong peak observed at $1700-1600 \mathrm{~cm}^{-1}$ is corresponding to the $\mathrm{C}=\mathrm{O}$ extension vibration, while in the range of $1300-1000 \mathrm{~cm}^{-1}$, the formation of C-O was observed. The IR spectra from Fig. 2 were confirmed the formation of PMAA nanoparticles prepared via emulsion polymerization technique and this observation was correlated with the similar pattern of IR spectra of PMAA nanoparticles that has been performed from the previous study [20]. Generally, by using different types of surfactant to synthesize PMAA nanoparticles, it shows that no significant effect to the formation of PMAA nanoparticles.

Thermogravimetric analysis (TGA): Thermogravimetric analysis is used to determine selected characteristics of materials that exhibit either mass loss or gain due to decomposition, oxidation, or loss of volatiles (such as moisture). It is also thermal analysis in which changes in physical and chemical properties of materials are measured as a function of increasing temperature. Fig. 3 shows the comparison of the percentage of weight loss corresponding to temperature changes by using different type of cationic surfactants at different concentrations.

The comparison of the weight loss of PMAA nanoparticles prepared using three different types of surfactants, CTAB,
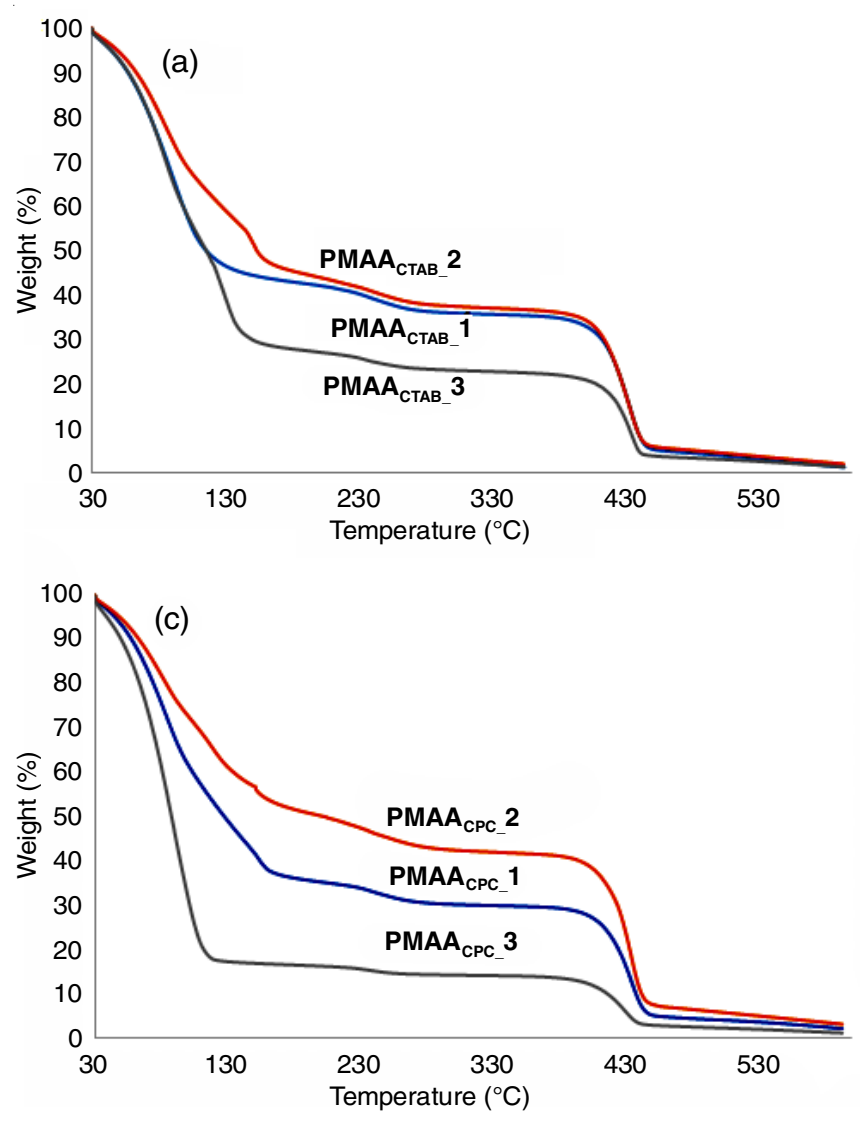

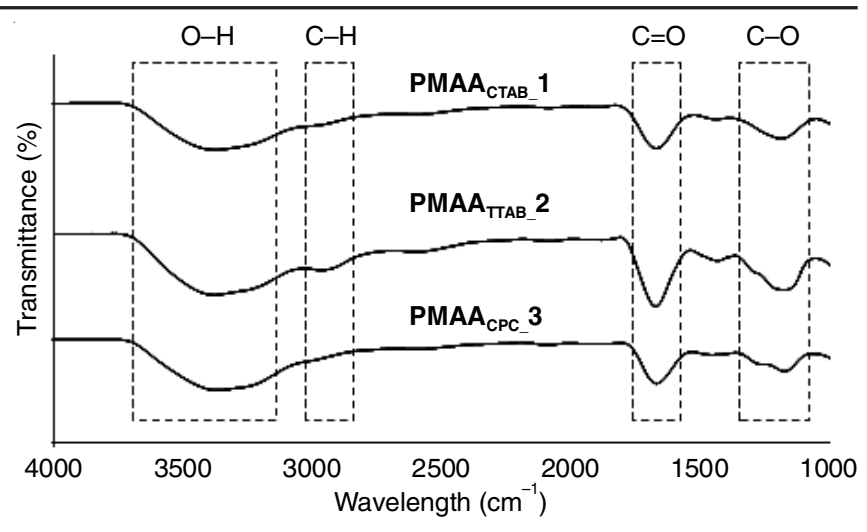

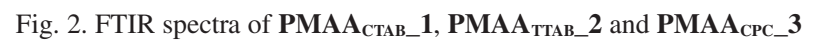

TTAB and CPC at different concentrations were depicted in Fig. 3a-c. Based on TGA curves in Fig. 3a, there are two distinct stages of weight loss. The initial weight loss is in a range of $100-144^{\circ} \mathrm{C}$ which perhaps on account of the present of moisture trace while the second weight loss is happened between 400 ${ }^{\circ} \mathrm{C}-420{ }^{\circ} \mathrm{C}$ which due to the onset degradation of polymer.

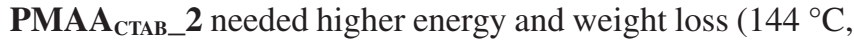
$56 \%)$ to degrade than PMAA $\mathbf{A}_{\text {Став_ }} \mathbf{1}\left(131{ }^{\circ} \mathrm{C}, 54 \%\right)$ and PMAA $_{\text {CTAB_}} 3\left(118{ }^{\circ} \mathrm{C}, 49 \%\right)$. In the second decomposition stage, the temperature and weight loss of PMA $\mathbf{A}_{\mathbf{C T A B}} \mathbf{1}$,

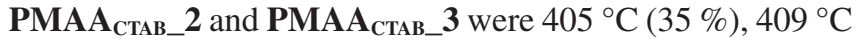
(37\%) and $406^{\circ} \mathrm{C}(22 \%)$, respectively. The thermal decompo-

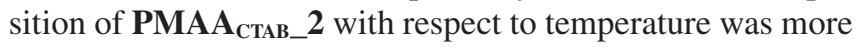

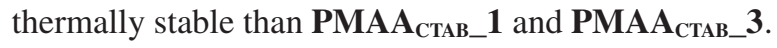
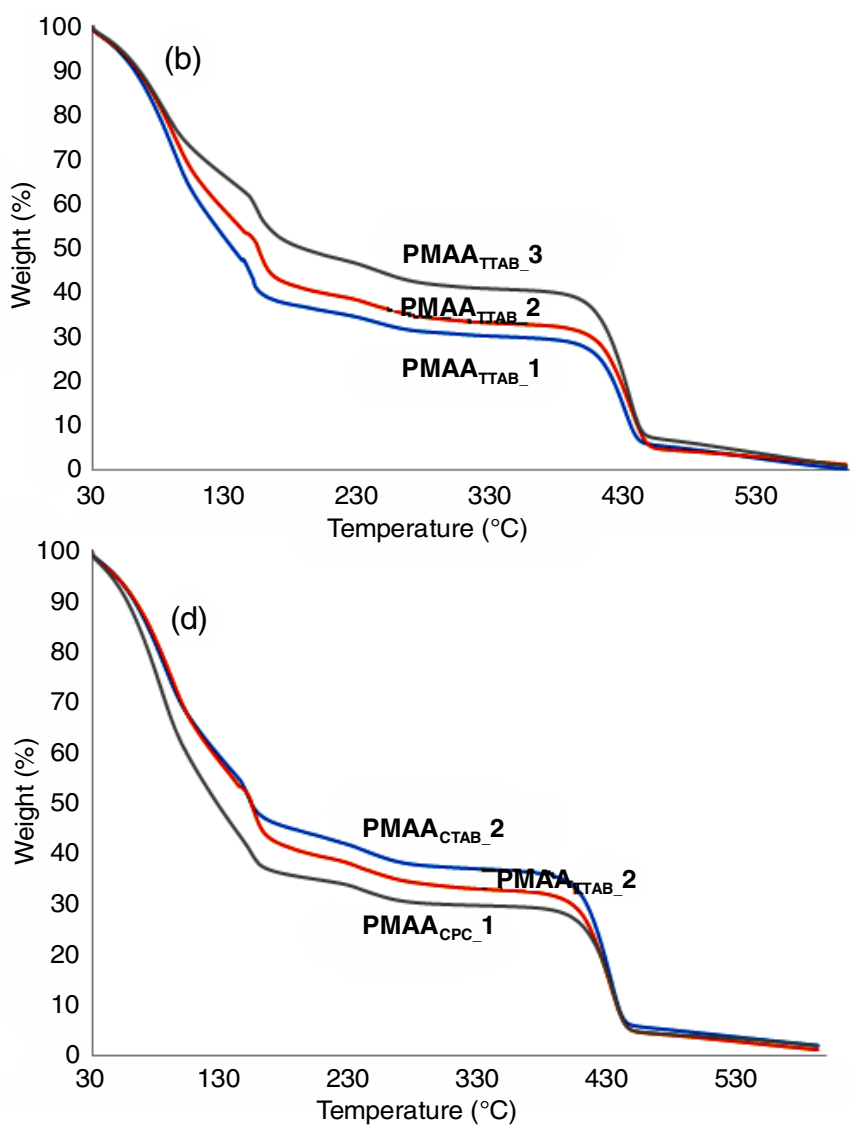

Fig. 3. TGA curves for PMAA nanoparticles synthesized using different types of non-ionic surfactants of (a) CTAB (b) TTAB and (c) CPC at different concentrations 
PMAA nanoparticles that prepared using TTAB as cationic surfactants at different concentrations (Fig. 3b) show that there are also two main zones of PMAA degradation within temperature rate at $142-150{ }^{\circ} \mathrm{C}$ and $406-408^{\circ} \mathrm{C}$. It is worth to mention that, the weight loss of PMA $\mathbf{A}_{\text {TTAB_}} \mathbf{1}\left(48 \%, 142{ }^{\circ} \mathbf{C}\right)$, PMA $\mathbf{P} \mathbf{A}_{\text {TTAB_2 }}$ $\left(53 \%, 150{ }^{\circ} \mathrm{C}\right)$ and PMAA $\mathbf{A}_{\text {TTAв_3 }}\left(45 \%, 142{ }^{\circ} \mathrm{C}\right)$ at initial temperature is may cause by releasing of bounded molecule of water [21]. Based on TGA curve (Fig. 3b) it indicates that the temperature for PMA $\mathbf{P} \mathbf{A}_{\mathbf{T T A B}} \_2\left(419^{\circ} \mathrm{C}, 65 \%\right)$ to degrade is higher at second stage degradation than PMAA $\mathbf{A}_{\text {TTAB_}} \mathbf{1}$ (407 $\left.{ }^{\circ} \mathrm{C}, 30 \%\right)$ and PMAA $\mathbf{A}_{\text {TTAB_}} 3\left(408{ }^{\circ} \mathrm{C}, 40 \%\right)$ as it required more greater energy to degrade. This observation proves that PMAA nanoparticles prepared using surfactants concentration at $\mathrm{CMC}$ is more thermally stable than preparation of PMAA nanoparticles by using surfactants concentration at below and above CMC.

Fig. $3 \mathrm{c}$ also shows that there are two significant weight loss regions (within $145-146{ }^{\circ} \mathrm{C}$ and $403-413{ }^{\circ} \mathrm{C}$ ) for PMAA nanoparticles prepared using $\mathrm{CPC}$ as cationic surfactants at different concentrations. It can be seen that the percentage weight loss of PMA $\mathbf{A}_{\mathbf{C P C} \_2}$ (58\%) started at higher initial temperature $\left(146{ }^{\circ} \mathrm{C}\right)$ than PMA $\mathbf{A}_{\mathbf{C P C}} \mathbf{1}(44 \%)$ and

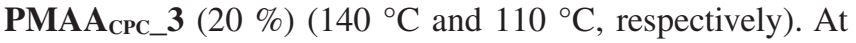
second stage, the residual weight of PMA $\mathbf{A}_{\mathbf{C P C} \_} \mathbf{2}$ onset temperature $\left(415^{\circ} \mathrm{C}\right)$ is $41 \%$ which have greater percentage of weight loss and resulting PMA $\mathbf{A} \mathbf{A}_{\mathbf{C P C} \_} \mathbf{2}$ is thermally more stable compared to PMAA $\mathbf{A}_{\mathbf{C P C} \_} \mathbf{1}(29 \%)$ and PMAA $\mathbf{A}_{\mathbf{C P C} \_3}$ (13 $\%)\left(403{ }^{\circ} \mathrm{C}\right.$ and $412{ }^{\circ} \mathrm{C}$, resepectively). From overall TGA data for PMAA nanoparticles prepared utilizing three types of surfactants (CTAB, TTAB and CPC), it can be concluded that the thermal stability of PMAA nanoparticles was improved with addition of the surfactants at $\mathrm{CMC}$ as the results obtained reflect the miscibility and hydrogen bonding interaction between the polymer component.

The multistages TGA curves which show comparison between three samples of greatest thermal stability among diffe-

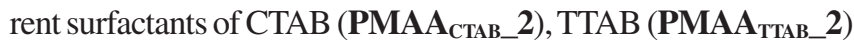
and CPC (PMAA $\mathbf{A}_{\mathbf{C P C} \_} 2$ ) was illustrate in Fig. 3d. It was found that, all PMAA samples that employed good thermal stability were prepared by using concentration of surfactants at equivalent CMC. However, the sample that achieved the best thermal stability is obtained from PMA $\mathbf{A} \mathbf{A}_{\mathbf{T T A B}} \mathbf{2}$ because it required higher temperature $\left(419{ }^{\circ} \mathrm{C}, 65 \%\right)$ to degrade compared to

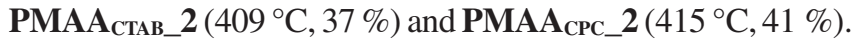
Thus, PMAA nanoparticles that synthesized using TTAB as cationic surfactant and prepared at CMC show better thermal stability in comparison to other types surfactants.

Scanning electron microscopy: The selected PMAA nanoparticles were further observed using scanning electron microscopy to measure their morphology and average particle sizes. The morphology of PMAA nanoparticles was not clearly be seen under SEM analysis on account of the limitation of SEM to observe materials at nanosized and the nature of polymer itself which cannot withstand higher temperature. However, from Fig. 4 it was clearly showed that PMAA nanoparticles, which prepared using different types of cationic surfactant at equivalent CMC (Fig. 4b, d and e) attained as spherical-like shape with homogenous distribution. PMAA nanoparticles synthesized using CPC at equivalent CMC (Fig. $4 \mathrm{e})$ show the existence of smaller particle size with agglomeration indicating that emulsion polymerization of PMAA utilizing CPC as surfactant needs higher concentration, which exceed CMC to achieve homogenous distribution of particles.

In contrast, large aggregation of PMAA nanoparticles were obtained from PMAA $\mathbf{A}_{\mathbf{C T A B} \_} \mathbf{1}$ (Fig. 4a) and PMA $\mathbf{A}_{\text {TTAB_}} \mathbf{1}$ (Fig. 4c) which prepared using CTAB and TTAB at surfactant below CMC. This observation shows that the concentration of surfactants could affect the structure and distributions of PMAA nanoparticles. Particle sizes of PMAA nanoparticles were also measured from SEM characterization by randomly measure the average particle size of each particle obtained from SEM images. The average particle sizes of PMAA nano-
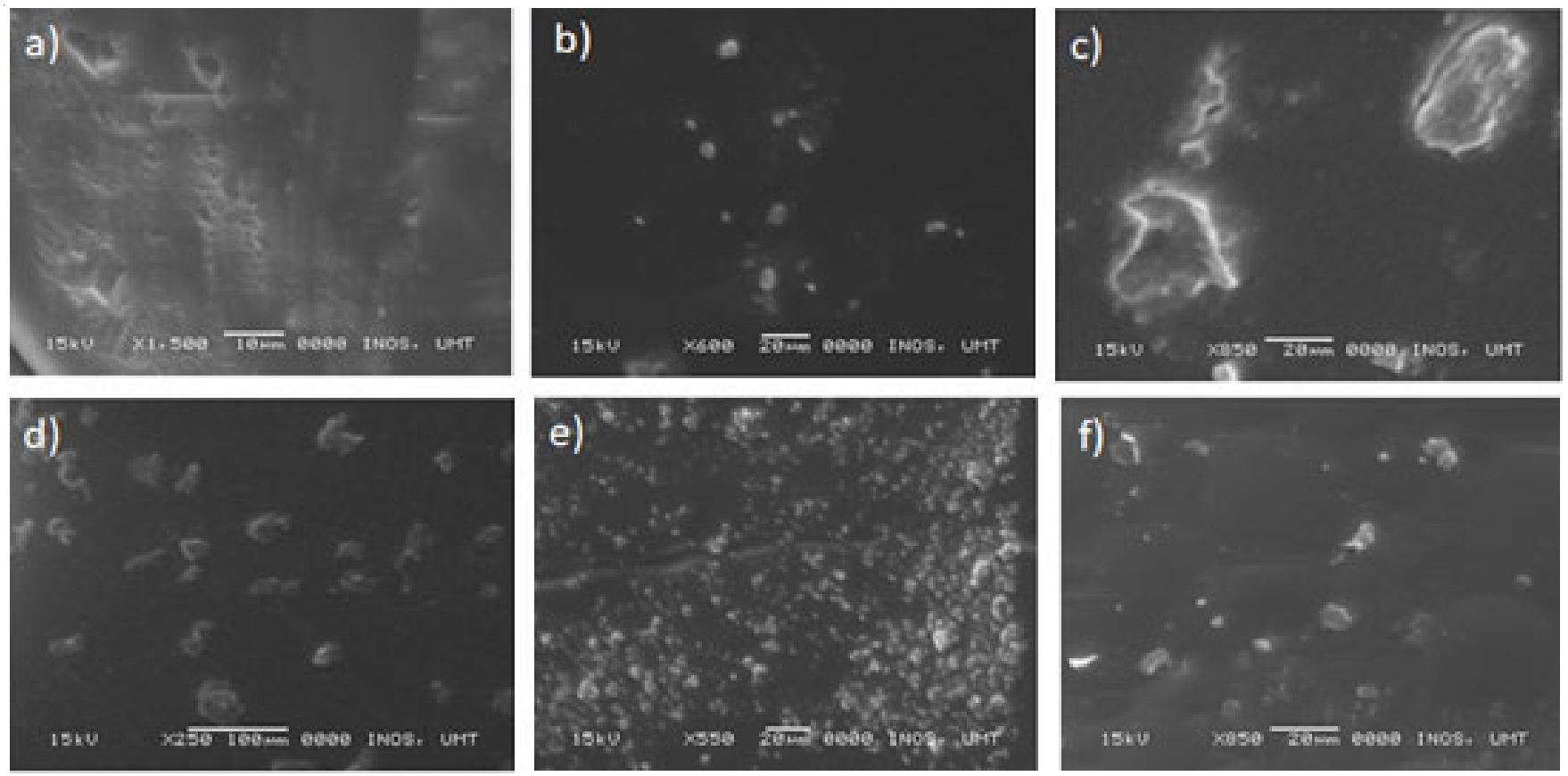

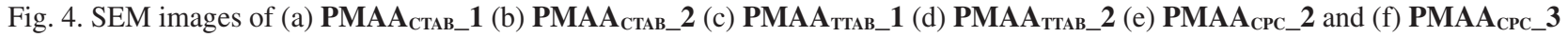


particles also affected by using different types of cationic surfactant at different concentrations, where PMAA nanoparticles prepared at surfactants concentration of equivalent and above

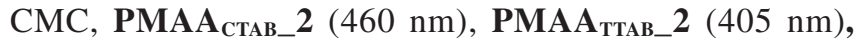
PMAA $_{\text {CPC_2 }}(442 \mathrm{~nm})$ and PMAA $\mathbf{A}_{\mathbf{C P C} \_}$3 $(470 \mathrm{~nm})$ showed smaller particle sizes. Meanwhile, PMAA $\mathbf{A}_{\mathbf{C T A B} \_} \mathbf{1}$ and PMAA $_{\text {TTAB__ }}$ 1, which obtained at surfactant concentrations of below CMC give larger particle sizes of $542 \mathrm{~nm}$ and $590 \mathrm{~nm}$, respectively.

Fig. 5 showed the particle size distribution of PMAA $\mathbf{A}_{\text {TтAB } \_2} 2$ obtained from dynamic light scattering (DLS). The measurement was performed after the polymerizations were completed. The particles sizes of PMAA $\mathbf{A T A B}_{\text {T2 } 2}$ obtained from DLS was $259 \mathrm{~nm}$ and showed narrow distribution $(\mathrm{PDI}=0.273)$. The particle size of PMAA $\mathbf{A}_{\text {TTAв_ }} 2$ observed from SEM is larger than DLS analysis. This observation is expected to happen on account of the nature of sample preparation for SEM analysis, which involved the evaluation of solid sample deposited on the sample holder and drying process of the sample.

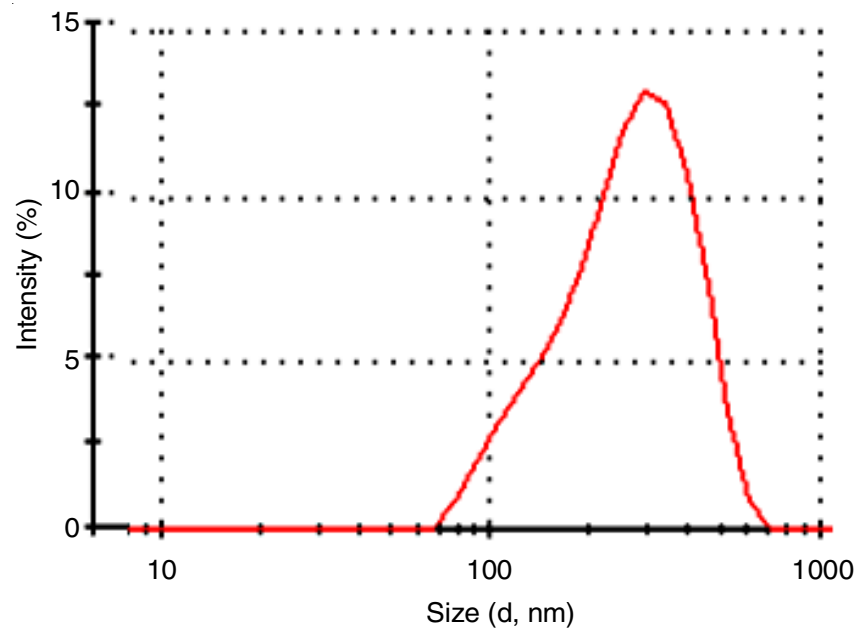

Fig. 5. Particle size distribution for PMAA $\mathbf{A}_{\text {TTAB_}} 2$ measured by DLS

\section{Conclusion}

The emulsion polymerization of PMAA nanoparticles has been successfully conducted using three different types of cationic surfactants at different concentrations of below, equivalent and above CMC. The formation of PMAA nanoparticles has been confirmed by Fourier transform infrared spectroscopy and all the PMAA nanoparticles samples obtained from different surfactants showed similar absorption spectra. Thermogravimetry analysis data shows that PMAA prepared at CMC of different cationic surfactants give better thermal stability of PMAA nanoparticles. Scanning electron microscopy showed the irregular structure of PMAA nanoparticles with average particles size in a range of $400-600 \mathrm{~nm}$. It was found that the different types and concentration of surfactants can effect the thermal stability and morphology of PMAA nanoparticles,

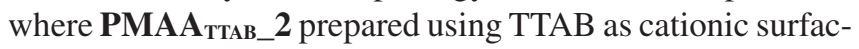
tant with surfactant concentration at equivalent CMC employs the best thermal stability and homogenous distribution of PMAA nanoparticles.

\section{ACKNOWLEDGEMENTS}

The authors express their gratitude to the Ministry of Higher Education, Malaysia and Universiti Malaysia Terengganu for the funding (FRGS 59344) and generous support to this research.

\section{CONFLICT OF INTEREST}

The authors declare that there is no conflict of interests regarding the publication of this article.

\section{REFERENCES}

1. S.S. Mirdamadi, M. Zohri, T. Gazori, A. Asadi and I. Haririan, Internet J. Nanotechnol., 3, 1 (2009).

2. S. Kassim, S.B. Zahari, R.A.A. Tahrin and N.A. Harun, AIP Conf. Proc., 1885, 020018 (2017);

https://doi.org/10.1063/1.5002212.

3. Y. Li, H. Wang, L. Xie, Y. Liang, G. Hong and H. Dai, J. Am. Chem. Soc., 133, 7296 (2011); https://doi.org/10.1021/ja201269b.

4. N.S. Abadeer and C.J. Murphy, J. Phys. Chem. C, 120, 4691 (2016); https://doi.org/10.1021/acs.jpcc.5b11232.

5. M.A. Majeed Khan, S. Kumar, M.Ahamed, S.A. Alrokayan and M. AlSalhi, Nanoscale Res. Lett., 6, 434 (2011); https://doi.org/10.1186/1556-276X-6-434.

6. Y. Zare, Compos., Part A Appl. Sci. Manuf., 84, 158 (2016); https://doi.org/10.1016/j.compositesa.2016.01.020.

7. R.A. Revia and M. Zhang, Mater. Today, 19, 157 (2016); https://doi.org/10.1016/j.mattod.2015.08.022.

8. M. Elsabahy and K.L. Wooley, Chem. Soc. Rev., 41, 2545 (2012); https://doi.org/10.1039/c2cs15327k.

9. N. Jawahar and S.N. Meyyanathan, Int. J. Health Allied Sci., 1, 217 (2012); https://doi.org/10.4103/2278-344X.107832.

10. V.G. Kadajji and G.V. Betageri, Polymers, 3, 1972 (2011); https://doi.org/10.3390/polym3041972.

11. A. Shalviri, G. Raval, P. Prasad, C. Chan, Q. Liu, H. Heerklotz, A.M. Rauth and X.Y. Wu, Eur. J. Pharm. Biopharm., 82, 587 (2012); https://doi.org/10.1016/j.ejpb.2012.09.001.

12. N.A. Harun, N.F.Z.M. Zain, M. Saadon and F.R.M. Rafi, J. Sustain. Sci. Manag., 12, 1 (2017).

13. H.B. Yamak, ed.: F. Yilmaz, Emulsion Polymerization: Effects of Polymerization Variables of Vinyl Acetate Based Emulsion Polymers, In: Polymer Science, InTech (2013); https://doi.org/10.5772/51498.

14. N. Anton, J.P. Benoit and P. Saulnier, J. Control. Rel., 128, 185 (2008); https://doi.org/10.1016/j.jconrel.2008.02.007.

15. A.M. Khan and S.S. Shah, J. Chem. Soc. Pak., 30, 186 (2008).

16. A. Sarac, B.F. Senkal and M. Yildirim, Am. J. Anal. Chem., 5, 17 (2014); https://doi.org/10.4236/ajac.2014.51003.

17. N.A. Harun, S. Kassim, S.T. Muhammad, F.E. Rohi, N.N. Norzam and N.S.M. Tahier, AIP Conf. Proc., 1885, 020032 (2017); https://doi.org/10.1063/1.5002226.

18. A. Shalviri, H.K. Chan, G. Raval, M.J. Abdekhodaie, Q. Liu, H. Heerklotz and X.Y. Wu, Colloids Surf. B Biointerfaces, 101, 405 (2013); https://doi.org/10.1016/j.colsurfb.2012.07.015.

19. E.M. Ahmed, J. Adv. Res., 6, 105 (2015); https://doi.org/10.1016/j.jare.2013.07.006.

20. Y. Wi, K. Lee, B.H. Lee and S. Choe, Macromol. Res., 17, 750 (2009); https://doi.org/10.1007/BF03218610.

21. G.S. Azhgozhinova, O. Güven, N. Pekel, A.V. Dubolazov, G.A. Mun and Z.S. Nurkeeva, J. Colloid Interface Sci., 278, 155 (2004); https://doi.org/10.1016/j.jcis.2004.05.010. 